\title{
The interplay between gonadal steroids and immune defence in affecting a carotenoid-dependent trait
}

\author{
Stefania Casagrande • Ton G. G. Groothuis
}

Received: 28 March 2011 /Revised: 30 May 2011 / Accepted: 31 May 2011 /Published online: 17 June 2011

(C) The Author(s) 2011. This article is published with open access at Springerlink.com

\begin{abstract}
The hypothesis that sexual ornaments are honest signals of quality because their expression is dependent on hormones with immune-depressive effects has received ambiguous support. The hypothesis might be correct for those signals that are carotenoid-dependent because the required carotenoid deposition in the signal, stimulated by testosterone, might lower the carotenoid-dependent immune defence of the organism. Two pathways underlying this androgen-dependent honest signaling have been suggested. Firstly, androgens that are needed for ornament expression may suppress immune defence, a cost that only high-quality animals can afford. Alternatively, immune activation may downregulate the production of androgens in low-quality individuals. Which of these alternatives is correct, and to what extent these effects are mediated by the different metabolites of androgens, remain open questions. To provide answers to these questions, we manipulated the levels of testosterone (T), $5 \alpha$-dihydrotestosterone (DHT), and $17-\beta$-estradiol (E2) in diamond doves Geopelia cuneata, a species in which both sexes exhibit a carotenoid-dependent, androgen-regulated red-orange periorbital ring of bare skin. On the first day of the experiment (day 0), we inserted steroid-releasing implants into groups of birds and on day 14 , we subjected half of the birds to an
\end{abstract}

Communicated by D. Rubenstein

S. Casagrande · T. G. G. Groothuis

Behavioural Biology, Centre for Behaviour

and Neuroscience, University of Groningen,

Nijenborgh 7,

9747 AG Groningen, The Netherlands

S. Casagrande $(\bowtie)$

Department of Evolutionary and Functional Biology,

University of Parma,

43100 Parma, Italy

e-mail: casagrande@biol.unipr.it immunological challenge by immunizing them with sheep red blood cells (SRBC). In females, but not in males, androgen but not estradiol treatments reduced antibody production to SRBC. In addition, the immunological challenge reduced redness and size of the trait as well as androgens levels in both sexes and in all treatments. This indicates that an immunological challenge can lower circulating $\mathrm{T}$ at the cost of the trait expression. These findings are in accordance with both pathways postulated in the immunocompetence-handicap hypothesis, but do not entirely support the idea that the immunosuppressive effect of androgens yields honest signaling since both T and DHT were not immunosuppressive in males, for which sexual signaling is supposed to be especially important.

Keywords ICHH · Ornament · Color · Testosterone · Estradiol $\cdot$ Dihydrotestosterone $\cdot$ SRBC $\cdot$ Humoral immunity

\section{Introduction}

To explain how honest signaling by means of extravagant secondary sexual traits (SST) can be stable in an evolutionary context, Hamilton and Zuk (1982) proposed that these displays could signal immune competence. The theory suggests that rapid adjustment of parasites to the immune defenses of the host requires a constant modification of the host's immune system, constraining the fixation of immune quality by directional selection. Consequently, immune competence varies among individuals of the same species and sexual signals may honestly signal the quality of the immune system of the bearer (Hamilton and Zuk 1982). In their frequently cited immunocompetencehandicap hypothesis (ICHH), Folstad and Karter (1992) proposed a mechanistic explanation for this by suggesting that only good quality males can sustain the immunosup- 
pressive cost (Zahavi 1975) of the high levels of testosterone $(\mathrm{T})$ required to express ornaments. The majority of studies testing the ICHH have considered one of the two pathways proposed by the model to explain the interaction between immune system and $\mathrm{T}$; that is, whether $\mathrm{T}$ is immunosuppressive. The results are ambiguous (reviewed in Roberts et al. 2004; Muehlenbein and Bribiescas 2005). Studies on birds and other animals showed that $\mathrm{T}$ may be immunosuppressive (Saino and Møller 1994; Duffy et al. 2000; Eens et al. 2000; Duckworth et al. 2001; Lindström et al. 2001; Mougeot et al. 2004), neutral (Weatherhead et al. 1993; Saino et al. 1995; Hasselquist et al. 1999; Klein et al. 1999; Ganley and Rajan 2001), or immunoenhancing (Marsh 1996; Ros et al. 1997; Granger et al. 2000; Peters 2000; McGraw and Ardia 2007).

Much less attention has been given to the alternative pathway proposed by the ICCH model, which states that the activation of the immune defence may lower $\mathrm{T}$ production, in turn leading to a lower expression of the sexual signal. This pathway is a likely alternative because of two findings. First, a recent meta-analysis showed evidence that immune activation suppresses $\mathrm{T}$ (Boonekamp et al. 2008). Second, other studies showed that parasite exposure lowers signal expression (reviewed in Møller et al. 1999). However, to our knowledge, no study has yet combined the analysis of both pathways.

Another reason for the ambiguous results of studies testing the immunosuppressive effect of $\mathrm{T}$ may be due to the diverse nature of sexual signals regulated by testosterone. Carotenoid-dependent SSTs are of particular interest for testing the $\mathrm{ICHH}$, especially those that consist of fleshy structures that can change rapidly in their expression, in contrast to feather coloration. Birds can absorb mainly xanthophylls (carotenoids without pro-vitamin A activity) that are involved in immune system regulation (reviewed in Chew and Park 2004). Xanthophylls are stored in many tissues, especially adipose tissue, liver, ovarian tissue, retinal tissues (Surai 2002), and skin (Casagrande et al. 2006), and they are mainly located in the cytosol (Vanhoutteghem et al. 2004) and in microorganelles such as mitochondrions (Chew and Park 2004). For example, they are stored in sebokerotinocytes, special avian cells of the integument, which are particularly efficient in regulating intracellular carotenoid concentration (Vanhoutteghem et al. 2004). Moreover, xanthophyll-based nonplumage traits are of special interest as the carotenoid deposition in these traits is enhanced by androgens (Witschi 1961; Mundinger 1979; Heath and Frederick 2006; McGraw 2006; McGraw et al. 2006; Mougeot et al. 2007). Since carotenoids have immune regulating functions (Bendich and Shapiro 1986; Blount et al. 2003; McGraw and Ardia 2003), and may be a limited resource (Blount 2004), their allocation to either the signal or other tissues can honestly indicate immune activation after an immune challenge (Faivre et al. 2003) or parasite infestation (Martínez-Padilla et al. 2007), suggesting the existence of a trade-off between signaling and health. In addition, the ambiguous results reported by tests of the immunosuppressive action of $\mathrm{T}$ may be due to the possibility that not $\mathrm{T}$ itself but one of its metabolites, such as dihydrotestosterone (DHT) or estradiol (E2), affect the immune system, and that this metabolism varies accordingly to environmental circumstances (see below).

In this study, we conducted a comprehensive test of the ICHH by testing both its pathways: the possible immunosuppressive effects of several gonadal steroids as well as the effect of immune activation on the production of these hormones, and both their relationship with the expression of a signal that depends on both androgens and carotenoid deposition. Since androgens and estrogens can have opposite effects on the immune system (Grossman 1985; Olsen and Kovacs 1996; Owen-Ashley et al. 2004), we simultaneously examined the effects of $\mathrm{T}$ and two metabolites of T, an androgen (DHT) and an estrogen (E2). T and DHT both bind to androgen receptors in target tissues and T can be converted locally to estrogenic metabolites by the enzyme aromatase, while DHT is non-aromatizable. Thus, immunosuppression by $\mathrm{T}$ and E2 but not DHT would indicate that $\mathrm{T}$-mediated immunosuppression is occurring through an indirect pathway mediated by estradiol. On the contrary, if DHT and $\mathrm{T}$ produce the same effect on the immune system, a direct effect through androgen receptors is more plausible. In addition, we expected that either the supplementation of androgens would lower the immune system response, or that the profiles of immunosuppressive steroids (androgens) will be lowered by the immune challenge, or both. In the last two cases, the trait expression, which is androgen-dependent, will also be lowered by the immune challenge.

We used the diamond dove Geopelia cuneata as a model species because both sexes have a relatively extensive red-orange periorbital ring of bare skin, which is carotenoid-dependent, regulated by $\mathrm{T}$ and DHT, and capable of rapid fluctuation of carotenoid content in the integument (Casagrande et al. 2011; Vanhoutteghem et al. 2004). Males have larger and more intensely colored periorbital rings than females (Voets 1980, Casagrande et al. 2011) and males' coloration becomes more intense during breeding time when gonadal hormones are elevated (Gray 1970; Casagrande et al. 2011). Thanks to these features, the periorbital ring of the diamond dove can be defined as a secondary sexual trait. Although we do not have evidence that this character is also a signal in mate choice or intersexual competition, we are not aware of evolutionary processes other than sexual selection that could explain the conspicuousness and the dimorphism of these secondary sexual traits (Darwin 1871). We tested 
both sexes, as studies of the ICHH in females are rare and may reveal general and sex-specific pathways (Eens et al. 2000). In diamond doves, androgens can enhance hue and size of the eye ring in both sexes, indicating a genetic correlation of trait expression as well as the possibility that the female signal is also under sexual selection (Casagrande et al 2011; Jones and Hunter 1993). With the present study, we tested whether immune system sensitivity to androgen and estrogen differs between the sexes and if the effect of an immune challenge on SST expression is consistent in the two sexes.

\section{Methods}

\section{Housing conditions}

The housing condition and the experimental design, together with the hormone levels registered on day 20 for non-immunized birds, have already been reported in Casagrande et al. (2011). The colony of 96 birds used for this experiment was housed at the Biology Department of the RUG University, in a room set to a constant temperature of approximately $20^{\circ} \mathrm{C}$ and with constant short photoperiod (8 L:16D) to prevent elevated gonadal hormone production. Birds were housed in pairs (male-female) in cages measuring $80 \times 40 \times 40 \mathrm{~cm}$ with three perches, and supplied with food (tropical seed mix) and water ab libitum. Birds were kept in an indoor flock for 4 weeks before pair housing and acclimatized to the pair-housing condition for 1 week prior to the insertion of hormone implants. Pairs were visually but not acoustically isolated from other pairs. The sex of each bird was initially checked by eye and it was then molecularly determined following Fridolfsson and Ellegren (1999). All birds were born in captivity and were acquired from an authorized pet shop.

\section{Design}

The design of the experiment is summarized in the time diagram (Fig. 1) where it is shown that the study started on the first of December (day 0), morphological measurements were taken and birds were implanted with either steroidfilled or empty implants. Fourteen days after implantation (day 14), blood samples were taken from all birds for initial antibody titres against sheep red blood cells (blood samples were not taken on day 0 to minimize interference with carotenoid availability; see Pérez-Rodrìguez et al. 2007). On the same day, half of the birds of each hormone implant group (six of each sex) were immunized with sheep red blood cells while the other birds received injections with saline (six of each sex per hormone treatment). On day 20 , all birds were blood sampled again for concentrations of hormones (to determine effectiveness of the implants and of the immune challenge on hormone levels) and antibodies (to determine the effect of the hormones on the antibody response). We are confident that the hormone levels released at day 20 closely resemble those at day 14 , since the implants were still full of hormone after day 20 , and because, day 20 levels should also not be higher than at day 14 , since the eye ring, which is very sensitive to the hormones (Casagrande et al. 2011), did not further increase after day 14. All blood samples (which were also used for molecular sexing to confirm the accuracy of sexing by eye) were taken from the wing vein with a heparinised syringe, kept cool for maximum $5 \mathrm{~h}$ until centrifugation at $14,000 \times g$ for $5 \mathrm{~min}$ to separate the plasma. Plasma was frozen at $-20^{\circ} \mathrm{C}$ until analysis. On days 0,14 , and 20, we measured the color and size of the orbital ring, and recorded body mass and skull length.

Birds were randomly assigned to one of the four steroid treatments: T (T), DHT (D), E2 (E), and control (C). Each treatment group consisted of 24 birds: 12 males and 12 females. Birds were housed in pairs to obtain a biologically relevant situation and minimize distress. To reach a balanced pairing condition with respect to treatment, we used all the possible combinations of treatments with the same frequency, obtaining three cages per each of the following combination (small letters refer to sex and capitals refer to hormone treatment): mT-fT, mT-fD, mT-fE, mT-fC, mE-fD, mE-fT, mE-fE, mE-fC, mC-fC, mC-fE, mCfD, mC-fT, mD-fC, mDHT-fE, mDHT-fD, and mD-fT.

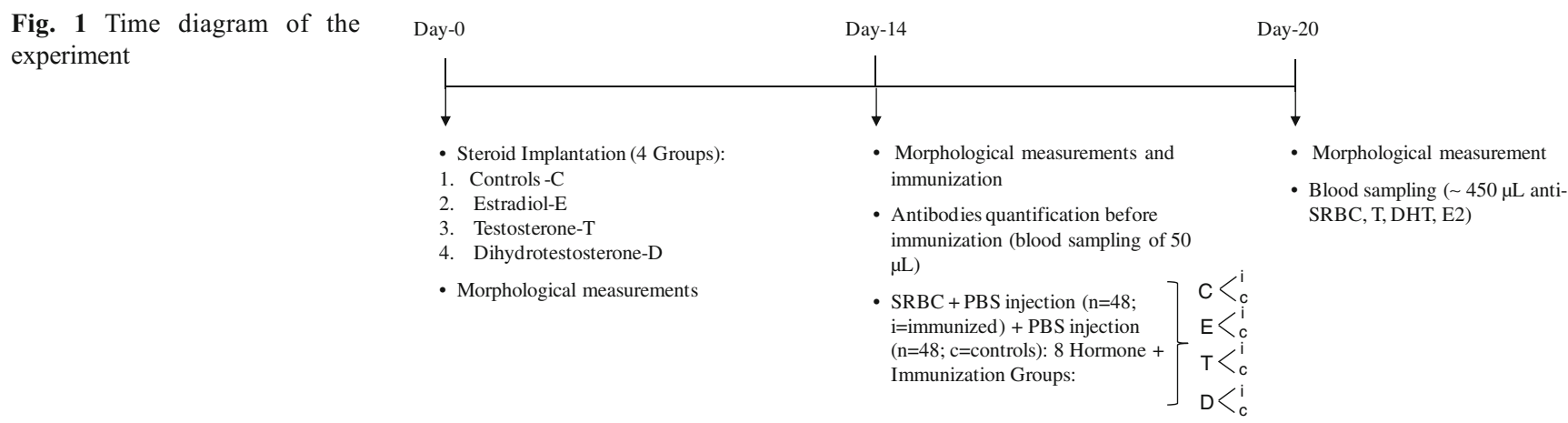


Final sample size was 94 birds as one non-immunized Etreated male and one immunized E-treated female died. In addition, three individuals were incorrectly sexed by eye at the start of the experiment. Thus, there was one cage with $2 \mathrm{C}$ males, one with $2 \mathrm{C}$ females and one with $2 \mathrm{~T}$ female and two cages with one male $\mathrm{E}$ and one female $\mathrm{C}$ alone. Since the steroid levels of these birds were well within the range of birds of the same sex and hormone treatment, and excluding incorrectly sexed birds from preliminary analyses did not affect results, we included all birds in the statistical analysis.

Implantation and blood sampling

Birds were implanted on day 0 with a silicone capsule (i.d. $=1.50 \mathrm{~mm}$, o.d. $=2.0 \mathrm{~mm}$; length, $12 \mathrm{~mm}$ ) filled with one of crystalline T, E2, or DHT (all from Sigma, St. Louis, MO, USA). Implants were immersed for $24 \mathrm{~h}$ in phosphate buffered saline (PBS) prior to implantation. Birds in the control group were implanted with empty tubes of the same size. The dimension of the implants was chosen based on results from previous studies conducted in birds of similar body mass that reported a physiological increase of steroids after implantation (Soma et al. 2000; Tramontin et al. 2003; Hunt and Wingfield 2004). We decided to provide both sexes with implants of the same size because the diamond dove is not sexually dimorphic in size or hormone levels (see "Result" section and Casagrande et al 2011) and because previous studies have implanted both sexes with implants of the same size (Eens et al. 2000; Hunt and Wingfield 2004; McGraw 2006; McGraw and Ardia 2007). Additionally, using similar implants allowed us to analyze between-sex differences within treatments. Birds were locally anesthetised with lidocaine (Xylocaine, AstraZeneca BV, Zoetermeer), the implant was inserted under the skin of the right flank, and the incision was sealed with surgical glue (HansaplastBeiersdforf, Hamburg, Germany). Implants were not removed after day 20 because birds were used for behavioral observations. During blood sampling and measurements, birds were handled for a maximum of 5 min each, both on days 14 and 20, by taking one bird at a time out of its cage with all sampling conducted out of sight from the other birds. Birds of all groups were handled identically for about the same amount of time.

\section{Humoral immunity}

A humoral immune response was induced on day 14 with an intraperitoneal injection of $350 \mu \mathrm{L}$ of $2 \%$ washed sheep red blood cells (SRBC) suspended in sterile PBS, following standard protocols (Deerenberg et al. 1997). Controls were injected with PBS only. Antibodies in the plasma of all birds were measured on the day of injection and 6 days after immunization (day 20), when antibodies titres of primary response reach maximum values (Ros et al. 1997; Verhulst et al. 2005). Antibodies were measured using a hemagglutination assay (Lawler and Redig 1984; Matson et al. 2005). Twenty microliter of plasma was diluted 1:1 with PBS and then serially diluted with $20 \mu \mathrm{l}$ of PBS in 96-well round-bottomed microtitre plates. A $20 \mu \mathrm{l}$ aliquot of $2 \%$ SRBC suspension was then added to each dilution and incubated at $37^{\circ} \mathrm{C}$ for $60 \mathrm{~min}$. The antibody response was expressed as the score (1-12) of the cell with highest dilution in which agglutinate antibodies were still detectable.

\section{Morphological measurements}

Measures of color and size of the periorbital ring, body mass and length of the skull (head+bill) were taken on days 0,14 , and 20 . The color of the sexual trait was assessed indoors under constant light and temperature conditions by measuring the reflectance of the eye ring every $0.35 \mathrm{~nm}$ using a portable spectrometer USB-2000 (configured range 250-850 $\mathrm{nm}$ ) and a light source deuterium-halogen DH-2000 (both Avantes, Erbeeck) and AvaSoft 5.0 (Avantes, Erbeeck). The probe, which holds both illuminating and recording optical fibers, was held at a right angle against the skin. After calibration with dark and white reference (WS-2, Avantes), we took three reflectance scans for each bird in a fixed location (the right side of the right eye ring), removing the probe between each scan. From the raw spectral data, we calculated the indices of hue using the spectral location of the midpoint between the minimum and the maximum value of the reflectance observed from 300 and $700 \mathrm{~nm}\left(\lambda_{\text {(Rmid) }}\right.$; Andersson et al. 2002). Mean values were considered after checking for repeatability $(r=0.80, p<0.001$, Lessels and Boag 1987). We chose hue as the colorimetric variable because this measure varied in both sexes after T and DHT administration (Casagrande et al. 2011). The length and width of the periorbital ring and the tarsus length were measured using a caliper to the nearest $0.1 \mathrm{~mm}$. An estimate of the total eye ring area was calculated as an ellipse surface, using the formula $\pi a b$, where $\pi$ is the mathematical constant and $a$ and $b$ are the semimajor (the longer axis) and the semiminor (the shorter axis) of the ellipse, respectively. To account for the area of the eye, we calculated the eye area as a circle with a mean diameter of $4.35 \pm 0.07 \mathrm{~mm}$ for 10 individuals (five males and five females) and subtracted that value from the periorbital area. Body mass was measured with a digital balance to the nearest $0.1 \mathrm{~g}$ and an index of body condition (BC) was calculated as the residuals of a linear regression of body mass on skull length (Chastel et al. 2005; $F_{(1,189)}=58.09, p<0.0001, R^{2}=0.24$ ). At the start of the experiment (day 0 ), no differences in hue, 
size of the eye ring, or body condition were observed between hormone and immunization treatment groups, nor between the sexes of those groups. This was tested in an analysis of variance (ANOVA) with future hormone treatment, immunization, and sex as fixed factors, allowing sex to interact with the first two factors (hue: hormone treatment, $F_{(3,86)}=1.57, p=0.20$, immunization treatment, $F_{(1,86)}=0.14, p=0.71$, sex, $F_{(1,86)}=2.17, p=0.15, \operatorname{sex} \times$ hormone treatment, $F_{(3,86)}=1.31, p=0.28$, sex $\times$ immunization treatment, $F_{(1,86)}=0.27, p=0.61$; size: hormone treatment, $F_{(3,86)}=0.73, p=0.54$, immunization treatment, $F_{(1,86)}=0.15$, $p=0.70$, sex, $F(1,86)=37.50, p<0.0001$, sex $\times$ hormone treatment, $F_{(3,86)}=0.55, p=0.65$, sex $\times$ immunization treatment, $F_{(1,86)}=0.07, p=0.80$; BC: hormone treatment, $F_{(3,86)}=1.03$, $p=0.39$, immunization treatment, $F_{(1,86)}=0.17, p=0.68$, sex, $F_{(1,86)}=1.85, p=0.18$, sex $\times$ hormone treatment, $F_{(3,86)}=$ $1.29, p=0.28$, sex $\times$ immunization treatment, $F_{(1,86)}=0.12$, $p=0.73$ ).

\section{Steroid radioimmunoassay}

Testosterone, E2, and DHT were assayed for all four hormone treatment groups. Samples were extracted twice adding to the plasma (circa 150-200 $\mu \mathrm{L}$ ) $4 \mathrm{~mL}$ of petroleum ether/diethylether (30-70\%) allowing steroids to pass from the watery phase to the organic one. The extraction was dried under a nitrogen stream and dissolved in $90 \%$ ethanol, dried again under a nitrogen stream, dissolved in $70 \%$ methanol and stored at $-20^{\circ} \mathrm{C}$ overnight. The solution was dried and dissolved in $185 \mu \mathrm{L}$ of PBSGbuffer. T was assayed from $50 \mu \mathrm{L}$ of plasma, using DSL4000 Active Testosterone Coated-Tube Radio immunoassay Kit (Diagnostic System Laboratories, Inc., Webster, TX, USA). DHT was assayed from $25 \mu \mathrm{L}$ of plasma using DSL96100 Dihydrotestosterone Radio immunoassay Kit (Diagnostic System Laboratories, Inc.) following the protocol provided with the kit. Estradiol was assayed in $50 \mu \mathrm{L}$ of plasma using DSL-4400 Estradiol Radioimmunoassay Kit (Diagnostic System Laboratories, Inc.) following the protocol of the kit. The concentrations of steroids are expressed in picograms per milliliter. Twenty microliter of plasma was used to assess extraction efficiency by counting the amount of radioactivity recovered. The intra- and inter assays coefficient of variation were, respectively, DHT, $1.57 \pm 0.16 \%$ and $6.66 \pm 0.88 \%$; E2, $4.96 \pm 1.11 \%$ and $6.30 \pm 0.95 \%$; T, $4.13 \pm 1.17 \%$ and $15.39 \pm$ $1.28 \%$ and average recovery rate was $83.03 \%$. Cross reactivity with steroids others than the target of the kit was very low (testosterone kit, $5.8 \%$ with $5 \alpha$ dihydrotestosterone, $2.3 \%$ with androstenedione, $0 \%$ with estrogens; $5 \alpha$-Dihydrotestosterone kit; androstandiol, $3.3 \%$; testosterone, $0.6 \%, 0 \%$ with estrogens; $17 \beta$ estradiol kit, $3.40 \%$ with estrone and $0 \%$ with androgens).
Data analysis

All analyses were performed with STATISTICA 7.0 (StatSoft 2004, Tulsa, OK, USA), using general linear model ANOVA models. We tested the effects of hormone treatment, immune challenge, sex, and their interactions on plasma hormone concentrations and on all the other dependent variables (the change in hue, size, and body condition) at day 20 . The latter were calculated as the difference in values before and after the immune challenge (day 20 minus day 14). The same models were used to analyze the variation of anti-SRBC production, performing the analysis within immunized birds only and considering hormone treatment and sex as fixed factors. Interactions and factors were sequentially removed from the models when nonsignificant $(p>0.05)$ following a standard backward procedure. Since body mass may influence the quantity of carotenoids deposited by birds in the skin of the ring (Perez-Rodriguez and Vinuela 2008) and since we found a correlation between body mass and, respectively, ring hue $(r=0.23, n=94, p<0.05)$ and ring size $(r=0.44, n=$ $94, p<0.05)$, we added body mass as covariate in the model when analyzing hue and size variation, but not body condition. We did not use repeated measures analyses to avoid three way interactions and because we are interested in representing the change of SST after immunization (original data are reported in Appendix 1). However, repeated measures ANOVA models gave the same results for the main effects. The effect of hormone treatment on color and size of the periorbital ring and on the body condition has already been detailed in Casagrande et al. (2011). Normality was tested with Shapiro-Wilcoxon tests. Data are reported as mean $\pm \mathrm{SE}$, and steroid levels were logtransformed to reach normal distributions.

\section{Results}

Effect of hormone treatment and immune challenge on hormone levels

Both androgens ( $\mathrm{T}$ and DHT) and E2 were significantly affected by hormone treatment and immune challenge (Table 1a-c, Figs 2a-c). As expected, since $\mathrm{T}$ can be metabolized to DHT, DHT concentrations were higher in the $\mathrm{D}$ and $\mathrm{T}$ treatment groups of immunized and nonimmunized birds compared to controls and E2-treated birds. T was elevated only in the $\mathrm{T}$ treatment group, while $\mathrm{E} 2$ was low in the $\mathrm{D}$ treatment group and in the T treatment group, indicating low levels of aromatase activity. Birds in the E treatment group had elevated E2 levels above those of the $\mathrm{T}$ and $\mathrm{D}$ group and above the immunized controls, but not above those of the non-immunized controls. However, 
Table 1 Variation of steroids with hormonal manipulation and SRBC challenge
Results of the GLM ANOVA for each steroid concentrations (DHT, T, and E2) considering sex, hormone treatment $(\mathrm{C}, \mathrm{E}, \mathrm{T}$, D) and immune challenge (immunized, non-immunized) and their interactions as fixed factors. Significant results are in bold

$C$ controls, $E$ estradiol, $T$ testosterone, $D$ dihydrotestosterone

\begin{tabular}{|c|c|c|c|c|c|c|}
\hline \multirow[t]{2}{*}{ Steroids } & \multicolumn{3}{|c|}{ Full model } & \multicolumn{3}{|c|}{ Final model } \\
\hline & $d f$ & $F$ & $P$ & $d f$ & $F$ & $P$ \\
\hline \multicolumn{7}{|l|}{ DHT } \\
\hline Sex $(S)$ & 1 & 1.59 & 0.21 & 1 & & \\
\hline Hormone treatment (HT) & 3 & 30.90 & $<0.0001$ & 3 & 29.73 & $<0.0001$ \\
\hline Immune challenge (IC) & 1 & 11.36 & 0.001 & 1 & 11.28 & $<0.01$ \\
\hline $\mathrm{S} \times \mathrm{HT}$ & 3 & 1.12 & 0.35 & 3 & & \\
\hline $\mathrm{S} \times \mathrm{IC}$ & 1 & 0.03 & 0.86 & 1 & & \\
\hline $\mathrm{HT} \times \mathrm{IC}$ & 3 & 1.98 & 0.12 & 3 & & \\
\hline $\mathrm{S} \times \mathrm{HT} \times \mathrm{IC}$ & 3 & 1.70 & 0.17 & 3 & & \\
\hline Error & 78 & & & 89 & & \\
\hline \multicolumn{7}{|l|}{$\mathrm{T}$} \\
\hline Sex (S) & 1 & 4.21 & 0.044 & 1 & 3.96 & 0.05 \\
\hline Hormone treatment $(\mathrm{HT})$ & 3 & 24.41 & $<0.0001$ & 3 & 22.77 & $<0.0001$ \\
\hline Immune challenge (IC) & 1 & 21.42 & $<0.0001$ & 1 & 21.77 & $<0.0001$ \\
\hline $\mathrm{S} \times \mathrm{HT}$ & 3 & 0.79 & 0.50 & 3 & & \\
\hline $\mathrm{S} \times \mathrm{IC}$ & 1 & 0.15 & 0.70 & 1 & & \\
\hline $\mathrm{HT} \times \mathrm{IC}$ & 3 & 0.51 & 0.68 & 3 & & \\
\hline $\mathrm{S} \times \mathrm{HT} \times \mathrm{IC}$ & 3 & 1.24 & 0.30 & 3 & & \\
\hline Error & 78 & & & 88 & & \\
\hline \multicolumn{7}{|l|}{ E2 } \\
\hline Sex $(S)$ & 1 & 0.69 & 0.41 & 1 & & \\
\hline Hormone treatment $(\mathrm{HT})$ & 3 & 16.69 & $<0.0001$ & 3 & 16.29 & $<0.0001$ \\
\hline Immune challenge (IC) & 1 & 10.32 & $<0.01$ & 1 & 11.17 & $<0.001$ \\
\hline $\mathrm{S} \times \mathrm{HT}$ & 3 & 1.51 & 0.22 & 3 & & \\
\hline $\mathrm{S} \times \mathrm{IC}$ & 1 & 0.13 & 0.72 & 1 & & \\
\hline $\mathrm{HT} \times \mathrm{IC}$ & 3 & 3.29 & 0.02 & 3 & 3.29 & 0.02 \\
\hline $\mathrm{S} \times \mathrm{HT} \times \mathrm{IC}$ & 3 & 0.50 & 0.69 & 3 & & \\
\hline Error & 78 & & & 86 & & \\
\hline
\end{tabular}

further testing for sex differences in this non-challenged group did reveal that E2 levels in E-treated males were higher than those in control males (least significant difference (LSD) post hoc, $p=0.05$ ). This was not the case in females who already had elevated levels (LSD post hoc, $p=0.91)$. Sex did not explain other variation in hormone levels, except for a borderline significance for $\mathrm{T}$ (Table 1b) and post-hoc tests for each treatment separately did not yield statistically significant effects for this hormone (LSD post-hoc tests, all $p>0.05)$. This comparison revealed that birds in the hormone control treatment that were not immunized did not show a significant sex difference in E2 levels. We conducted the same analysis for both androgens, revealing that control groups of males and females showed comparable levels of T (LSD post hoc $p=0.48$ ) and DHT (LSD post hoc $p=0.56$ ).

The immune challenge significantly lowered the levels of all three hormone concentrations (Table 1). Post hoc tests revealed that this was especially the case for DHT in birds not treated with androgens (Fig 1a), which is to be expected since in the other groups the androgen implants would continuously elevate androgens. $T$ was significantly suppressed by the immune challenge in three of the four groups, even in the group treated with the hormone itself (Fig. 2b). E2 was only significantly suppressed in the control group, as also indicated by the significant effect of the interaction between hormone treatment and immunization treatment (Fig. 2c, Table 1).

\section{Effect of hormonal manipulation on antibody response}

None of the birds in the control treatment of the immune response test showed any production of antibodies; that is all these birds had zero scores in the heamogluttination test. Thus, the measured titre of agglutination after injection with the antigen was a valid measure of the response of the humoral component of the immune system (Fig. 3). Within the group of immunized birds, the interaction of hormone treatment and sex significantly affected SRBC antibody production $\left(\operatorname{sex} \times\right.$ hormone treatment, $F_{(3,39)}=7.58, p<$ 

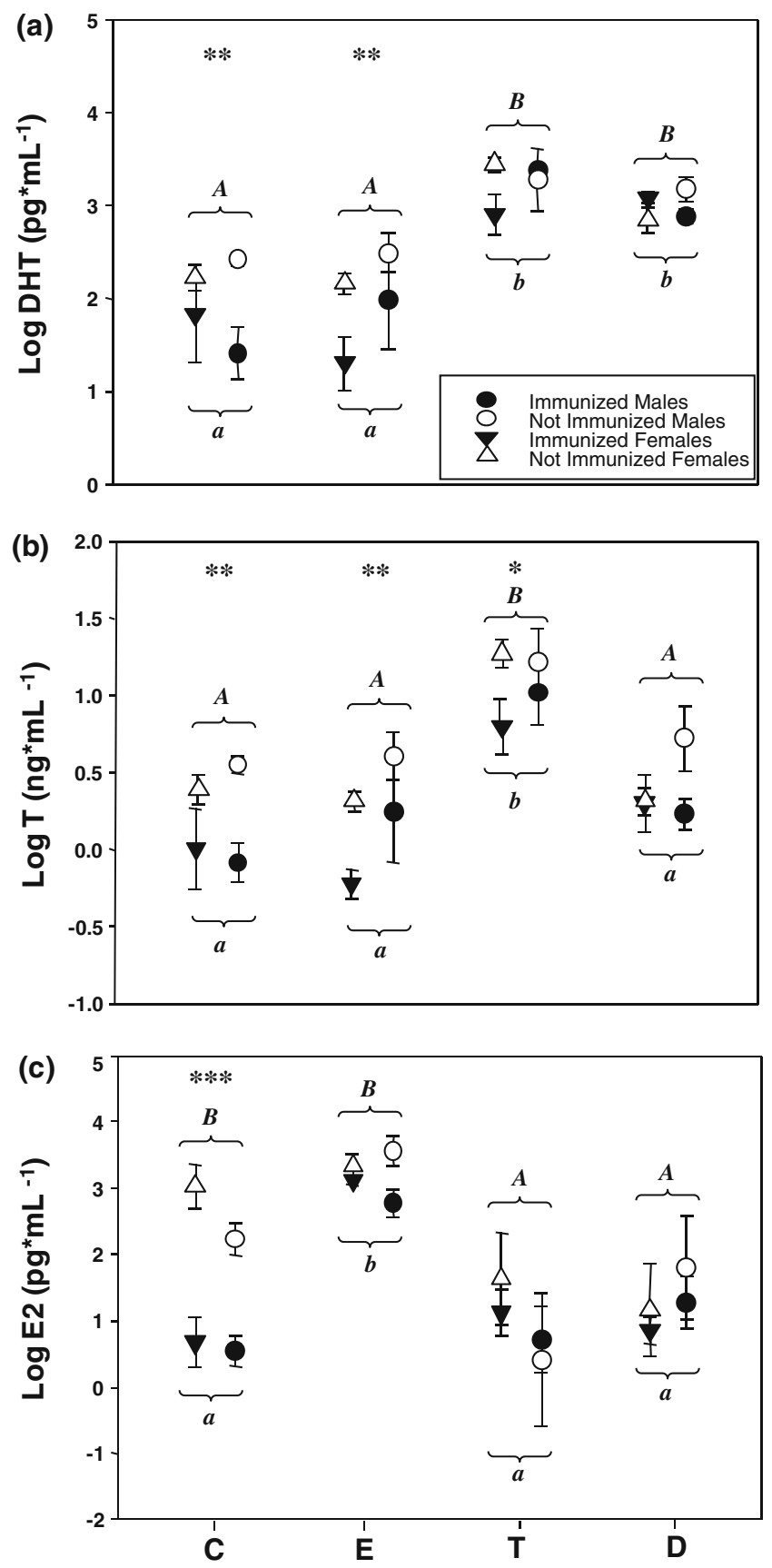

Fig. 2 Variation in steroid concentrations ( $a$ DHT, $b$ T, $c$ E2) at day 20 as a consequence of steroid manipulation starting at day $0(C$ empty implants, $E$ E2 implants, $T$ T implants, $D$ DHT implants) and immune challenge with SRBC (at day 14), presented for each sex separately. Different letters refer to results of Fisher's LSD post hoc analysis (small for immune-challenged and capital for non-immunechallenged birds) indicating significant differences relative to $\mathrm{C}$ birds among hormone treated birds analyzed within the same immunization treatment. Asterisks refer to significant differences between different immunization treatments of the same steroid group $\left(* * * p<0.001,{ }^{* *} p<0.01,{ }^{*} p<0.05\right)$. Values (shapes) represent mean \pm SE (vertical bars). Sex differences are not reported because we did not found any interaction between sex and other factors
0.001; hormone treatment, $F_{(3,39)}=9.34, p<0.0001$; sex, $\left.F_{(1,39)}=1.41, p=0.24\right)$. Because of this interaction, we tested the effect of hormone treatment on antibody titres for each sex separately. Male anti-SRBC production was not affected by hormone treatment $\left(F_{(3,20)}=2.29, p=0.11\right)$ whereas female anti-SRBC titres were $\left(F_{(3,19)}=17.59, p<\right.$ 0.0001). Post hoc tests for females revealed that the humoral response was suppressed by T and DHT (Fig. 3).

Interestingly, males showed a lower degree of immune response compared to females in all hormone-treatment groups except D and T (Fig. 3). Nevertheless, the lack of a suppressive effect of androgens on antibody titres in males is not due to the relatively low titres in males in general (a floor effect), since females show substantial lower titres in the $\mathrm{T}$ group than males (Fig. 3). The sex effect on the antibody response is intriguing since hormone levels did not show a consistent sex effect. The latter was specifically checked by post hoc testing of sex differences in hormone levels for each hormone-treatment group of immunechallenged birds separately. This showed that sex effects on hormone concentrations were far from significant for each hormone, except for estradiol in D- and T-treated birds (slightly higher E2 levels for females in $\mathrm{T}$ group and for males in $\mathrm{D}$ group; $p=0.06$ in both cases, $p>0.17$ in all other cases).

Effect of hormones and immunization on the secondary sexual trait and body condition

The hue of the eye ring was lowered following the immune challenge (Table 2a, Fig. 4a). There was no effect of sex or

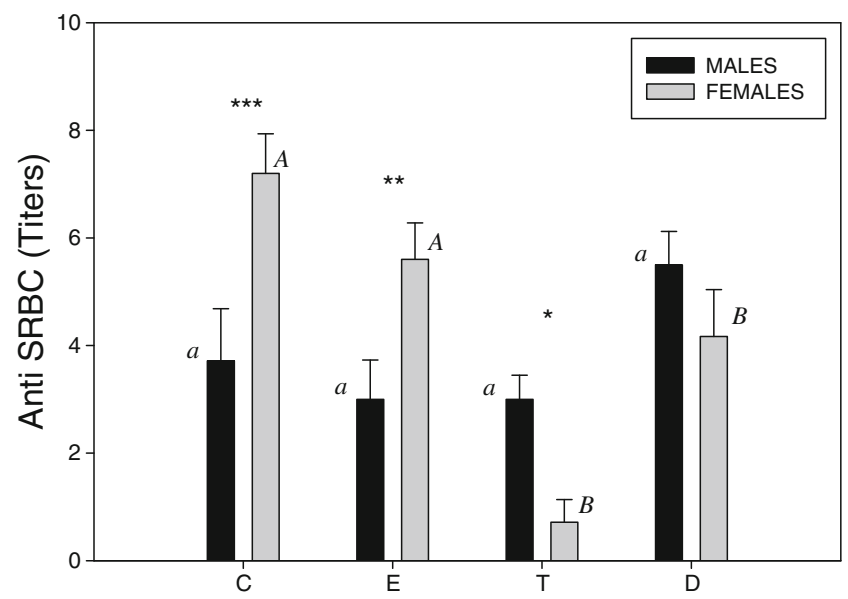

Fig. 3 Anti-SRBC response of immunized birds $(n=47)$ of both sexes in each steroid treatment $(C, E, T$, and $D)$. Different letters above the columns refer to significant differences within each sex among the four implant groups (small for males and capital for females), asterisks to significant differences between sexes of the same group tested with Fisher's LSD post hoc analysis $\left(* * * p<0.001, *^{*} p<0.01,{ }^{*} p<0.05\right)$. Values (bars) represent mean $\pm \mathrm{SE}$ (vertical bars) 
a significant two- or three-way interaction between sex, hormone treatment, and immune challenge on the shading (shifting toward yellow) in eye color. Likewise, the immunization resulted in a decrease in the size of the eye ring (Table 2b; Fig. 4b), irrespective of hormone treatment and sex and interactions.

The differences in body condition between days 20 and 14 were explained only by hormone treatment (Table 2c; Fig. 5), without any interaction between hormone treatment and either immunization or sex (Table 2c). Post hoc tests between hormone treatments revealed that none of the groups differed from controls (C-E, $p=0.12$; C-T, $p=0.11 ; \mathrm{C}-\mathrm{D}, p=0.47$ ) while body condition was higher in $\mathrm{T}$ treatment groups compared to E- $(p=0.002)$ and D-treated birds $(p=0.02)$. No differences in body condition were found between E- and Dtreatment groups $(p=0.39)$.

\section{Discussion}

The ICHH, explaining honest signaling on the basis of a causal relation between androgens, trait expression and immunocompetence, has received a lot of attention in the past decade. Nevertheless, evidence is still ambiguous (see "Introduction" section). Most attention has been given to the hypothesis that $\mathrm{T}$ is immunosuppressive. We tested the potential immunosuppressive effect of $\mathrm{T}$ as well as two of its metabolites, DHT, and E2. In addition, we tested the reverse pathway, also postulated in the $\mathrm{ICHH}$, that an immunological challenge suppresses steroid production, resulting in a decrease in signal expression. We studied an androgen-dependent trait, the color and size of the periorbital ring in both sexes of the diamond dove, a trait that requires carotenoids, which are also probably involved in immune defence. Our study yielded evidence
Table 2 Results of ANOVA models explaining variation in colour and size of the eye ring and in body condition
Results of GLM Univariate ANCOVA for SST parameters (hue and size) and Body condition considering sex, hormone treatment $(\mathrm{C}, \mathrm{E}, \mathrm{T}, \mathrm{E})$ and immune challenge (immunized, non-immunized) as fixed factors. Significant results are in bold.

$C$ controls, $E$ estradiol, $T$ testosterone, $D$ dihydrotestosterone

\begin{tabular}{|c|c|c|c|c|c|c|}
\hline \multirow[t]{2}{*}{ SST } & \multicolumn{3}{|c|}{ Full model } & \multicolumn{3}{|c|}{ Final model } \\
\hline & $d f$ & $F$ & $P$ & $d f$ & $F$ & $P$ \\
\hline \multicolumn{7}{|l|}{ Hue } \\
\hline Weigh, day 20 & 1 & 0.76 & 0.39 & 1 & 3.86 & 0.05 \\
\hline $\operatorname{Sex}(\mathrm{S})$ & 1 & 0.59 & 0.45 & & & \\
\hline Hormone treatment $(\mathrm{HT})$ & 3 & 1.65 & 0.18 & & & \\
\hline Immune challenge (IC) & 1 & 3.26 & 0.07 & 1 & 4.00 & 0.048 \\
\hline $\mathrm{S} \times \mathrm{HT}$ & 3 & 0.19 & 0.90 & & & \\
\hline $\mathrm{S} \times \mathrm{IC}$ & 1 & 0.03 & 0.86 & & & \\
\hline $\mathrm{HT} \times \mathrm{IC}$ & 3 & 0.24 & 0.87 & & & \\
\hline $\mathrm{S} \times \mathrm{HT} \times \mathrm{IC}$ & 3 & 0.14 & 0.94 & & & \\
\hline Error & 77 & & & 91 & & \\
\hline \multicolumn{7}{|l|}{ Size } \\
\hline Weigh, day 20 & 1 & 0.15 & 0.70 & & & \\
\hline Sex $(S)$ & 1 & 0.17 & 0.68 & & & \\
\hline Hormone treatment $(\mathrm{HT})$ & 3 & 0.46 & 0.71 & & & \\
\hline Immune challenge (IC) & 1 & 4.56 & 0.04 & 1 & 4.76 & 0.03 \\
\hline $\mathrm{S} \times \mathrm{HT}$ & 3 & 1.96 & 0.13 & & & \\
\hline $\mathrm{S} \times \mathrm{IC}$ & 1 & 0.41 & 0.52 & & & \\
\hline $\mathrm{HT} \times \mathrm{IC}$ & 3 & 1.27 & 0.29 & & & \\
\hline $\mathrm{S} \times \mathrm{HT} \times \mathrm{IC}$ & 3 & 0.59 & 0.62 & & & \\
\hline Error & 77 & & & 92 & & \\
\hline \multicolumn{7}{|l|}{ Body condition } \\
\hline Sex $(S)$ & 1 & 3.11 & 0.08 & & & \\
\hline Hormone treatment $(\mathrm{HT})$ & 3 & 3.90 & 0.012 & 3 & 3.66 & 0.02 \\
\hline Immune challenge (IC) & 1 & 0.22 & 0.64 & & & \\
\hline $\mathrm{S} \times \mathrm{HT}$ & 3 & 1.19 & 0.32 & & & \\
\hline $\mathrm{S} \times \mathrm{IC}$ & 1 & 0.02 & 0.88 & & & \\
\hline $\mathrm{HT} \times \mathrm{IC}$ & 3 & 2.28 & 0.09 & & & \\
\hline $\mathrm{S} \times \mathrm{HT} \times \mathrm{IC}$ & 3 & 0.77 & 0.52 & & & \\
\hline Error & 78 & & & 90 & & \\
\hline
\end{tabular}



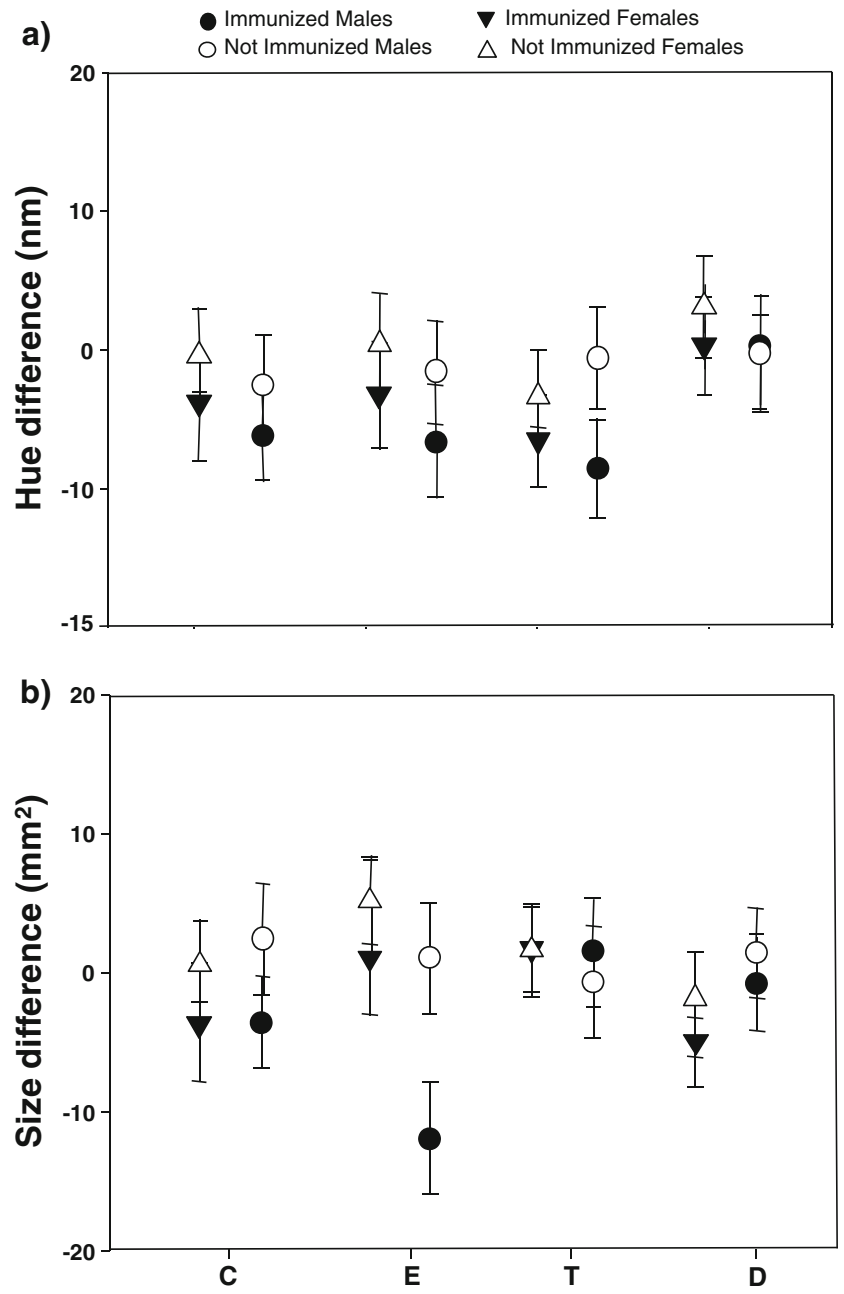

Fig. 4 Eye ring hue (a) and area (b) difference between days 20 and 14 presented for each steroid and immune challenge treatment separately and for each sex. Values (shapes) represent mean $\pm \mathrm{SE}$ (vertical bars). Hue values were corrected for weigh measured on day 20. For further details, see legend in Fig. 1

for both pathways postulated in the ICHH, partly in a sex dependent way.

Immunosuppressive effect of gonadal steroids

It is currently accepted that males and females differ in immune competence as males typically show a weaker immune response to a variety of antigens than do females (Klein 2000; Stoehr and Kokko 2006) and the data from the $\mathrm{C}$ and $\mathrm{E}$ birds is consistent with this. In females, both $\mathrm{T}$ and DHT treatments lowered antibody response to SRBC, whereas there was no such effect in males. Interestingly, this sex difference was not related to sex differences in the concentration of circulating androgens. The lack of effect from $\mathrm{T}$ and DHT in males is also not due to a floor effect in that sex, since antibody titres in T-treated males were higher than those in T-treated females. Perhaps the female immune system is more sensitive to enhanced levels of androgens than males, which normally experience higher levels of these hormones than females (reviewed in Møller et al. 2005). It has been shown that females can tolerate high levels of androgens without downregulating the color and size of the periorbital ring (Casagrande et al. 2011), and here we demonstrate that non-immunized $\mathrm{C}$ females had levels of androgens and estrogen comparable to males, indicating that the steroid profiles do not differ substantially between the two sexes in natural conditions. We now also demonstrate that the signal is condition dependent in the females.

The immunosuppressive effect of androgens may also not have shown up in males because males are more colored than females and have larger rings for carotenoid deposition. This suggests that they have more carotenoid available for buffering the immunosuppressive effect of $\mathrm{T}$, in accordance with the theory proposed by Blas et al. (2006) and McGraw and Ardia (2007). However, this explanation does not fit our data as we have not found any sex effect in the degree of hue and size loss in the periorbital ring, indicating no difference in the amount of pigments withdrawn from the skin for buffering immunosuppression. Moreover, correcting the humoral response for hue loss value after immunization did not affect the sex difference in immune suppression at all (data not shown). The sex difference in the capacity to store carotenoids in the eye ring that could buffer the immunosuppressive effects is also unlikely to be very important for the overall storage capacity, as large amounts of carotenoids can be deposited in liver and fat tissues, a possibility that requires further study.

This is the first study that specifically shows androgens, but not the androgen metabolite estradiol, to be immuno-

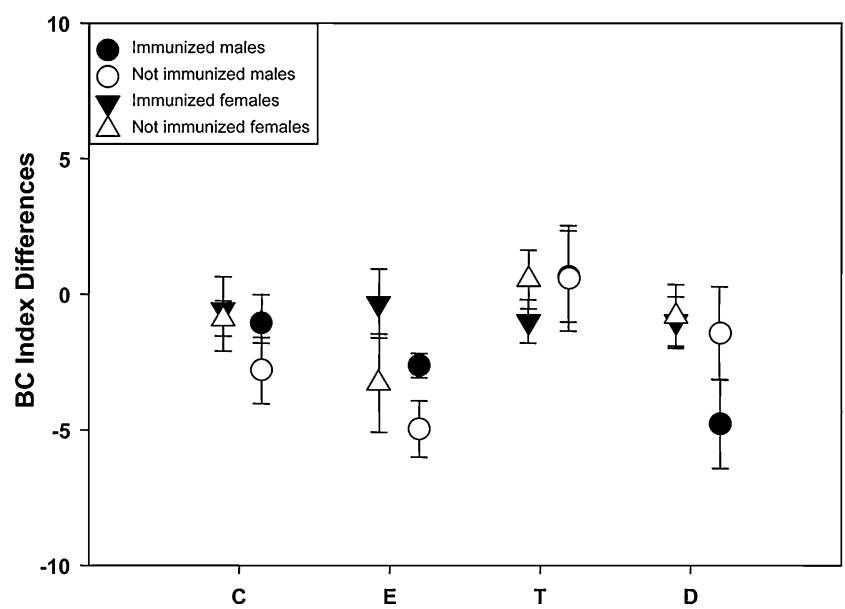

Fig. 5 Body condition (BC) index change after immunization (difference between days 20 and 14). Asterisks refer to significant differences between immunization treatments within the same hormone group tested with Fisher's LSD post hoc analysis $\left({ }^{*} p<0.05\right)$. Values (shapes) represent mean $\pm \mathrm{SE}$ (vertical bars). For further details, see legend in Fig. 1 
suppressive (at least in females), indicating a role for androgen receptors and not estrogen receptors or aromatase. These findings are concordant with what has been found in male mice, where both $\mathrm{T}$ and DHT are immunosuppressive (Samy et al. 2001). However, the finding that the gonadal steroids were not immunosuppressive in males, for which sexual signaling is supposed to be especially important, is evidence against the immunosuppressive effect of androgens yielding honest signaling as postulated in the ICHH.

Hormone suppression by immune activation

As far as we know, this is the first study showing that an immune challenge not only depresses steroid profiles but that this also goes at the cost of signaling, as indicated by the downregulation of signal expression in immunized birds. Our results are in line with previous work by Peters et al. (2004), who found a negative correlation between antibodies and plasma testosterone concentration but, as the authors themselves specified in their discussion, only an experimental approach such as the one we conducted in this study can unequivocally demonstrate that investment in antibody production is the cause of the decline in testosterone as well as signal expression. Our experiment represents clear support for the least-tested pathway underlying honest signaling as postulated in the ICHH. Suppression of steroid levels due to an immunological challenge has been demonstrated by a recent metaanalysis (Boonekamp et al. 2008) as has been the reduction of color-based signaling by immunological challenges (McGraw and Ardia 2003; Faivre et al. 2003). However, the simultaneous occurrence of these results in one and the same group of individuals has, to the best of our knowledge, not yet been reported. Moreover, since the signal we studied is carotenoid dependent, the results are consistent with the idea that testosterone may underlie the allocation trade-off between signaling and immune enhancing functions of carotenoids, indicating honest signaling. Nevertheless, as stated above, carotenoid storage in other tissues may be more important for immune defence than those in the eye ring. Perhaps by lowering signal expression, the animal reduces the chances of being involved in costly social interactions when immunologically challenged, a time when it needs resources for immune defence.

Birds were not castrated and within the birds not treated with hormones, the lower levels of plasma hormone concentrations measured in the immunized birds compared to the non-immunized birds is therefore most likely due to a decrease in hormone production. More remarkable are the lower levels of steroid hormones in immunized birds treated with hormones, since the treatment was expected to continuously elevated hormone levels and downregulate endogenous production by affecting the HPG feedback axis. Although we cannot be certain that endogenous production was very low, gonads after vivisection were strongly reduced in these birds. The lower hormone levels due to an immune challenge and despite a hormone implant, therefore may suggest that an immune challenge can not only affect hormone production but also hormone clearance and or metabolism. Endocrine suppression after an immune challenge could be an adaptive response, not only for avoiding immune suppression, but also for reallocating metabolic energy and resources (carotenoids) towards immune function (Wedekind and Folstad 1994; Verhulst et al. 1999), since mounting an immune response can be costly (Lochmiller and Deerenberg 2000; Martin et al. 2003). Moreover, we suggest that by downregulating gonadal steroid production, the animal downregulates its sexual signal as an adaptive response, in order to avoid competition from other males in better condition.

The immunization did not have any effect on body condition. This suggests that energy allocation for the activation of the immune system in response to a nonpathogenic antigen is not related to body mass. However, given the ad libitum food conditions, our birds could have compensated for the increased metabolic energy demand by eating more food and reducing locomotory activity, as observed in captive greenfinches (Carduelis chloris) treated with SRBC (Hõrak et al. 2003).

In conclusion, this study showed for the first time that $\mathrm{T}$ regulated signals are honest not-or not only-because $\mathrm{T}$ (and not E2) is immunosuppressive, but because the immune response depresses the endogenous production of the hormone which affects signal expression. The same holds true for DHT. Although an immune challenge also lowered estradiol, a metabolite from T, estradiol does not affect signal expression, indicating an androgen-specific role for signal control.

Acknowledgments We are grateful to James Tagliavini for extra laboratory facilities and laboratory analysis assistance, to Cor Dijkstra and Vivian Goerlich for helping with implantation and blood sampling, and to Bonnie deVries for helping with radioimmunoassay analyses. We are grateful to two anonymous referees for improving the quality of this manuscript and to Mary Ryan and Shaun Killen for the English revision of the text. The study has been funded by the European Union within the 6th Framework Program (EIF Marie Curie Project n. 025369-HormColour, 20062008). All experiments were carried out under specific licenses of the Dutch government and the University Ethical Committee for animal experiments.

Open Access This article is distributed under the terms of the Creative Commons Attribution Noncommercial License which permits any noncommercial use, distribution, and reproduction in any medium, provided the original author(s) and source are credited. 


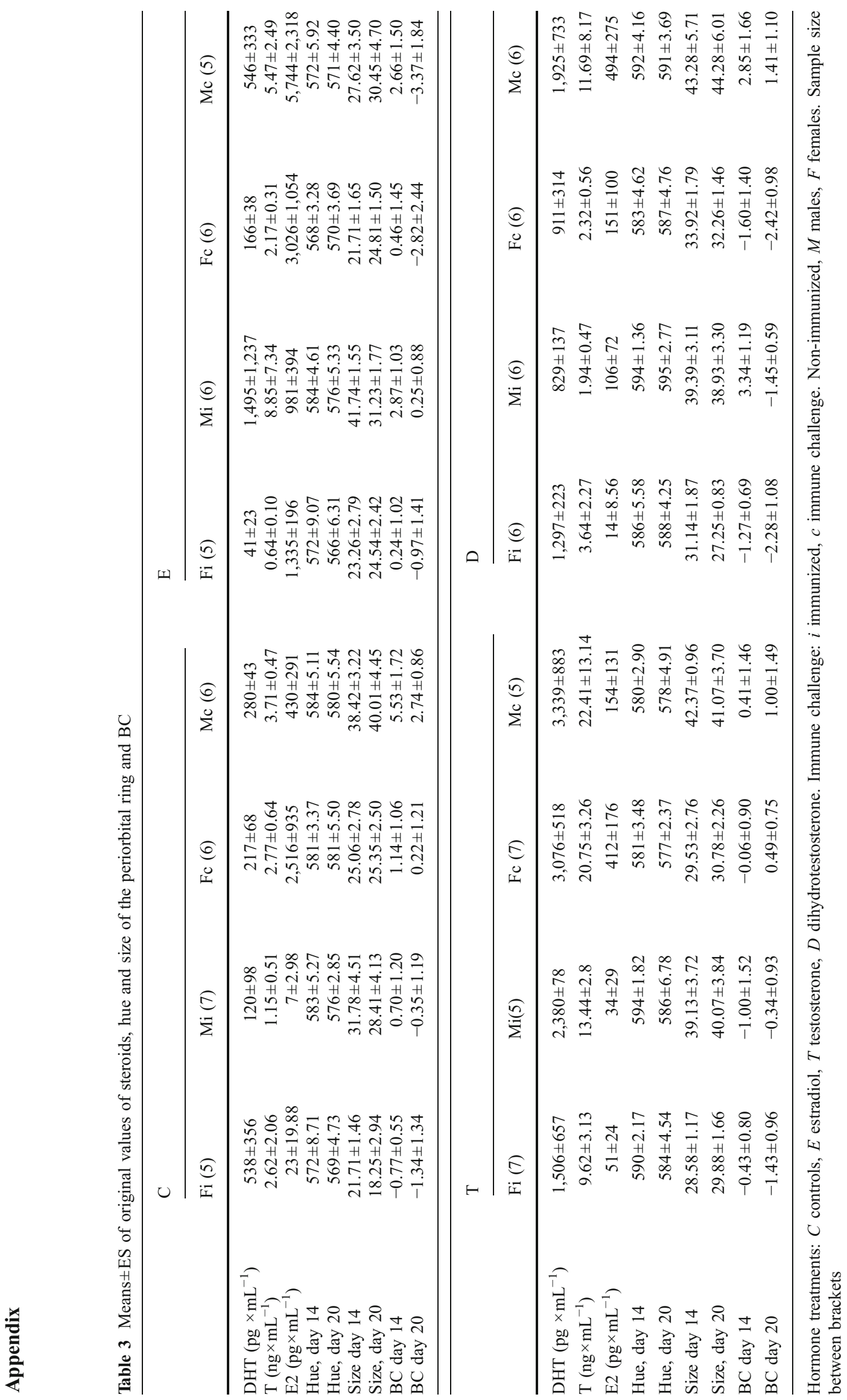




\section{References}

Andersson S, Pryke SR, Ornborg J (2002) Multiple receivers, multiple ornaments, and a trade-off between agonistic and epigamic signaling in a widow bird. Am Nat 160:683-691. doi:10.1086/342817

Bendich A, Shapiro SS (1986) Effect of B-carotene and canthaxanthin on the immune response of the rat. J Nutr 116:2254-2262

Blas J, Perez-Rodriguez L, Bortolotti GR, Vinuela J, Marchant TA (2006) Testosterone increases bioavailability of carotenoids: insights into the honesty of sexual signaling. Proc Nat Acad Sci USA 103:18633-18637. doi:10.1073/pnas.0609189103

Blount JD (2004) Carotenoids and life-history evolution in animals. Arch Biochem Biophys 430:10-15

Blount JD, Metcalf NB, Birkhead R, Surai PF (2003) Carotenoid modulation of immune function and sexual attractiveness in zebra finches. Science 300:125-127. doi:10.1126/science.1082142

Boonekamp JJ, Ros AHF, Verhulst S (2008) Immune activation suppresses plasma testosterone level: a meta-analysis. Biol Lett 4:741-744. doi:10.1098/rsbl.2008.0347

Casagrande S, Csermely D, Pini E, Bertacche V, Tagliavini J (2006) Skin carotenoid concentration correlates with male hunting skill and territory quality in the kestrel (Falco tinnunculus). J Avian Biol 37:190-196. doi:10.1111/j.0908-8857.2006.03515.x

Casagrande S, Dijkstra S, Tagliavini J, Goerlich V, Groothuis T (2011) Differential effects of testosterone, dihydrotestosterone and estradiol on carotenoid deposition in an avian sexually selected signal. J Comp Physiol A 197:1-13. doi:10.1007/s00359-010-0579-4

Chastel O, Lacroix A, Weimerskirch H, Gabrielsen GW (2005) Modulation of prolactin but not corticosterone responses to stress in relation to parental effort in a long-lived bird. Horm Behav 47:459-466. doi:10.1016/j.yhbeh.2004.10.009

Chew BP, Park JS (2004) Carotenoid action on the immune response. J Nutr 134:257S-261S

Darwin C (1871) The descent of man; and selection in relation to sex. Cambridge Library Collection (2009 Edition). Cambridge: Cambridge University Press. pp: 251-320.

Deerenberg C, Apanius V, Daan S, Bos N (1997) Reproductive effort decreases antibody responsiveness. Proc R Soc Lond B 264:1021-1029

Duckworth RA, Mendonca MT, Hill GE (2001) A condition dependent link between testosterone and disease resistance in the house finch. Proc R Soc Lond B 268:2467-2472. doi: $10.1098 / \mathrm{rspb} .2001 .1827$

Duffy DL, Bentley GE, Drazen DL, Ball GF (2000) Effects of testosterone on cell-mediated and humoral immunity in nonbreeding adult European starlings. Behav Ecol 11:654-662

Eens M, Van Duyse EV, Berghman L, Pinxten R (2000) Shield characteristics are testosterone-dependent in both male and female moorhens. Horm Behav 37:126-134. doi:10.1006/ hbeh.1999.1569

Faivre B, Grégoire A, Préault M, Cézilly F, Sorci S (2003) Immune activation rapidly mirrored in a secondary sexual trait. Science 300:103. doi:10.1006/anbe.2003.2142

Folstad I, Karter AJ (1992) Parasites, bright males, and the immunocompetence handicap. Am Nat 139:603-622. doi:10.1086/285346

Fridolfsson AK, Ellegren H (1999) A simple and universal method for molecular sexing of non-ratite birds. J Avian Biol 30:116-121

Ganley L, Rajan TV (2001) Endogenous testosterone levels do not affect filarial worm burdens in mice. Exp Parasitol 98:29-34

Granger DA, Booth A, Johnson DR (2000) Human aggression and enumerative measures of immunity. Psychosom Med 1:217-227

Gray M (1970) The fallow dove. International Dove Society Newsletter. Available from: http://www.internationaldovesociety. com/articles/thediamonddove.htm.
Grossman CJ (1985) Interactions between the gonadal steroids and the immune system. Science 227:257-261. doi:10.1126/science. 3871252

Hamilton WD, Zuk M (1982) Heritable true fitness and bright birds: a role for parasites? Science 218:384-387. doi:10.1126/science. 7123238

Hasselquist D, Marsh JA, Sherman PW, Wingfield JC (1999) Is avian humoral immunocompetence suppressed by testosterone? Behav Ecol Sociobiol 45:167-175

Heath JA, Frederick PC (2006) White Ibis integument color during the breeding season. J Field Ornithol 77:141-150. doi:10.1111/ j.1557-9263.2006.00034.x

Hõrak P, Saks L, Ots I, Kullissaar T, Kollist H, Zilmer M (2003) Physiological effects of immune challenge in captive greenfinches (Carduelis chloris). Can J Zool 81:371-379

Hunt KE, Wingfield JC (2004) Effect of estradiol implants on reproductive behavior of female Lapland longspurs (Calcarius lapponicus). General Comp Endocrinol 137:248-262.

Jones IL, Hunter FM (1993) Mutual sexual selection in a monogamous seabird. Nature 362:238-239

Klein SL (2000) Hormones and mating system affect sex and species differences in immune function among vertebrates. Behav Proc $51: 149-166$

Klein SL, Gamble HR, Nelson RJ (1999) Role of steroid hormones in Trechinella spiralis infection among voles. Am J Physiol Regul Integr Comp Physiol 277:R1362-R1367

Lawler EM, Redig PT (1984) The antibody responses to sheep red blood cells of the Red-tailed hawk and great-horned owl. Dev Comp Immunol 8:733-738

Lessels CM, Boag PT (1987) Unrepeatable repeatabilities: a common mistake. Auk 104:116-121

Lindström KM, Krakover D, Lundstrom JO, Silverin B (2001) The effects of testosterone on a viral infection in greenfinches (Carduelis chloris): an experimental test of the immunocompence-handicap hypothesis. Proc R Soc Lond B 268:207211. doi: $10.1098 / \mathrm{rspb} .2000 .1352$

Lochmiller RL, Deerenberg C (2000) Trade-offs in evolutionary immunology: just what is the cost of immunity? Oikos 88:8798. doi:10.1034/j.1600-0706.2000.880110.x

Marsh JA (1996) The integration of the nueroendocrine and immune systems: a marriage of convenience or necessity. In: Davison TF et al (eds) Poultry immunology. Abingdon, Carfax

Martin LB, Scheuerlein A, Wikelski M (2003) Immune activity elevates energy expenditure of house sparrow: a link between direct and indirect costs? Proc R Soc Lond B 270:153-158. doi:10.1098/rspb.2002.2185

Martínez-Padilla J, Mougeot F, Pérez-Rodríguez L, Bortolotti GR (2007) Nematode parasites reduce carotenoid-based signalling in male red grouse. Biol Lett 3:161-164. doi:10.1098/rsbl.2006.0593

Matson KD, Ricklefs RE, Klasing KC (2005) A hemolysis-hemagglutination assay for characterizing constitutive innate humoral immunity in wild and domestic birds. Dev Comp Immunol 29:275-286. doi:10.1016/j.dci.2004.07.006

McGraw KJ (2006) Sex steroid dependence of carotenoid-based coloration in female zebra finches. Physiol Behav 88:347-352. doi:10.1016/j.physbeh.2006.04.003

McGraw KJ, Ardia DR (2003) Carotenoids, immunocompetence, and the information content of sexual colors: an experimental test. Am Nat 162:704-712. doi:10.1086/378904

McGraw KJ, Ardia DR (2007) Do carotenoids buffer testosteroneinduced immunosuppression? An experimental test in a colourful songbird. Biol Lett 3:375-378. doi:10.1098/rsbl.2007.0190

McGraw KJ, Correa SM, Adkins-Regan E (2006) Testosterone upregulates lipoprotein status to control sexual attractiveness in a colorful songbird. Behav Ecol Sociobiol 60:117-122. doi:10.1007/s00265-005-0135-3 
Møller AP, Christe P, Lux E (1999) Parasitism, host immune function, and sexual selection. Q Rev Biol 74:3-20

Møller AP, Garamszegi LZ, Gil D, Hurtrez-Boussès S, Eens M (2005) Correlated evolution of male and female testosterone profiles in birds and its consequences. Behav Ecol Sociobiol 58:534-544

Mougeot F, Irvine JR Seivwright, Redpath SM L, Piertney S (2004) Testosterone, immunocompetence, and honest sexual signalling in male red grouse. Behav Ecol 15:930-937. doi:10.1093/ beheco/arh087

Mougeot F, Perez-Rodriguez L, Martinez-Padilla J, Leckie F, Redpath SM (2007) Parasites, testosterone and honest carotenoid-based signalling of health. Funct Ecol 21:886-898. doi:10.1111/j.13652435.2007.01302.x

Muehlenbein MP, Bribiescas RG (2005) Testosterone-mediated immune functions and male life histories. Am J Hum Biol 17:527558. doi:10.1002/ajhb.20419

Mundinger PC (1979) Annual testicular cycle and bill color change in the eastern American goldfich. Auk 89:403-419

Olsen NJ, Kovacs WJ (1996) Gonadal steroids and immunity. Endocr Rev Ecol 17:369-384

Owen-Ashley NT, Hasselquist D, Wingfield JC (2004) Androgens and the immunocompetence handicap hypothesis: unraveling direct and indirect pathways of immunosuppression in song sparrows. Am Nat 164:490-505

Perez-Rodriguez L, Vinuela J (2008) Carotenoid-based bill and eye ring coloration as honest signals of condition: an experimental test in the red-legged partridge (Alectoris rufa). Naturwissenschaften 95:821-830

Pérez-Rodrìguez L, Alonso-Alvarez C, Vinuela J (2007) Repeated sampling but not sampling hour affects plasma carotenoid levels. Physiol Biochem Zool 80:250-254

Peters A (2000) Testosterone treatment is immunosuppressive in superb fairy-wrens, yet free-living males with high testosterone are more immunocompetent. Proc R Soc Lond B 267:883-889. doi:10.1098/rspb.2000.1085

Peters A, Delhey K, Denk AG, Kempenaers B (2004) Trade-offs between immune investment and sexual signaling in male mallards. Am Nat 164:51-59. doi:10.1086/421302

Roberts ML, Buchanan KL, Evans MR (2004) Testing the immunocompetence handicap hypothesis: a review of the evidence. Anim Behav 68:227-239. doi:10.1016/j.anbehav.2004.05.001

Ros AHF, Groothuis TGG, Apanius V (1997) The relation among gonadal steroids, immunocompetence, body mass, and behavior in young black-headed gulls (Larus ridibundus). Am Nat 150:201-219. doi:10.1086/286063
Saino N, Møller AP (1994) Secondary sexual characters, parasites and testosterone in the barn swallow, Hirundo rustica. Anim Behav 48:1325-1333

Saino N, Møller AP, Bolzerna AM (1995) Testosterone effects on the immune system and parasite infections in the barn swallow (Hirundo rustica): an experimental test of the immunocompetence hypothesis. Behav Ecol 6:397-404

Samy TSA, Knoferl MW, Zheng R, Schwacha MG, Bland KI, Chaudry IH (2001) Divergent immune responses in male and female mice after trauma-hemorrhage: dimorphic alterations in $\mathrm{T}$ lymphocyte steroidogenic enzyme activities. Endocrinology 142:3519-3529

Soma KK, Tramontin AD, Wingfield JC (2000) Oestrogen regulates male aggression in the non-breeding season. Proc R Soc Lond B 267:1089-1096. doi:10.1098/rspb.2000.1113

Stoehr AM, Kokko H (2006) Sexual dimorphism in immunocompetence: what does life-history theory predict? Behav Ecol 17:751-756

Surai PF (2002) Natural antioxidants in avian nutrition and reproduction. University Press, Nottingham

Tramontin AD, Wingfield JC, Brenowitz EA (2003) Androgens and estrogens induce seasonal-like growth of song nuclei in the adult songbird brain. J Neurobiol 57:130-140. doi:10.1002/neu.10263

Vanhoutteghem A, Londero T, Ghinea N, Djian P (2004) Serial cultivation of chicken keratinocytes, a composite cell type that accumulates lipids and synthesizes a novel $\beta$-keratin. Differentiation 72:123-137

Verhulst S, Dieleman SJ, Parmentiers HK (1999) A trade-off between immunocompetence and sexual ornamentation in domestic fowl. Proc Nat Acad Sci USA 96:4478-4481

Verhulst S, Riedstra B, Wiersma P (2005) Brood size and immunity costs in zebra finches Taeniopygia guttata. J Avian Biol 36:2230. doi:10.1111/j.0908-8857.2005.03342.x

Voets P (1980) The diamond dove. International Dove Society Newsletter. Available from: http://www.internationaldovesociety. com/articles/thediamonddove.htm

Weatherhead PJ, Metz KJ, Bennett GF, Irwin RE (1993) Parasite faunas, testosterone and secondary sexual traits in male redwinged blackbirds. Behav Ecol Sociobiol 33:13-23

Wedekind C, Folstad I (1994) Adaptive and non adaptive immunosuppression by sex-hormones. Am Nat 143:936-938. doi:10.1086/285641

Witschi E (1961) Sex and secondary sexual characters. In: Biology and comparative physiology of birds. Academic Press, New York

Zahavi A (1975) Mate selection - a selection for a handicap. J Theoret Biol 53:205-214 